Talía. Revista de estudios teatrales

ISSN-e 2659-806X

\title{
¿Cómo es que asomó el Caballero de la Triste Figura? En busca de un contexto para las fiestas de 1607 en Pausa
}

\author{
Laura Agar Paz Rescala*
}

Recibido: 20 de diciembre de 2019 / Aceptado: 3 de febrero de 2020

Resumen: Este estudio trata sobre aquellos famosos torneos que se teatralizaron en 1607 en la localidad peruana de Pausa. Están testimoniados en una anónima relación de fiestas descubierta por Rodríguez Marín; pero, el hecho de que se sepa tan poco de la historia virreinal de Pausa ha ocasionado que se conviertan en una suerte de mito, tanto para Pausa, como para el cervantismo, pues, en fecha tan cercana a la primera edición del Quijote, este personaje es representado en las virreinales justas. Mi intento es el de ubicar el hecho en su propia historia local. Para hacerlo, primero, propongo un análisis de las tradiciones festivas que circulaban en el territorio y que pudieron dar pie al quijotesco torneo. Luego, expongo mi propuesta sobre el contexto más inmediato de la fiesta y del manuscrito que la contiene: sobre los grupos de poder que habrían estado por detrás y los intereses que podían haber barajado, para esto resultará esencial un expediente jurídico encontrado en el Cusco.

Palabras clave: Perú, don Quijote, política, teatro y fiesta.

\section{[en] How come the Knight of the Sad Countenance appeared? In search of the context of the 1607 festivals in Pausa}

\begin{abstract}
This study is about the famous theater tournaments that occurred in the Peruvian locality of Pausa in 1607. The evidence of this competition exists in an anonymous relación de fiestas discovered by Rodríguez Marín. However, due to the lack of researches about the history of Pausa, the event has converted into kind of a myth for both the locality and for Cervantes-studies because the date is so close to the first edition of the Don Quixote and due to the appearance of the famous character into the tournaments. My intention in the following work is to place the event within its own local history. First, I offer an analysis of festive traditions that circulated in the territory and that could led up to the Quixotic competition. Later, I propose an hypothesis about the larger context of the festival and the manuscript in which the account of it is contained. This includes an analysis of the powerful social groups that would have been behind the exposition and their interests in the event. For this, a juridical document found in Cuzco will be essential.
\end{abstract}

Key word: Perú, don Quixote, politics, theater and festivities.

Cómo citar: Paz Rescala, L. A. (2020). ¿Cómo es que asomó el Caballero de la Triste Figura? En busca de un contexto para las fiestas de 1607 en Pausa, en Talía. Revista de estudios teatrales, 2, 91-98.

A tal empresa solicita y llama cuantos en las antárticas regiones quieren ganar por sí gloriosa fama.

Cartel de desafío en la fiesta de Nuestra Señora de Guadalupe.

En esta ocasión me dispongo a afrontar un tema sobre el cual, como pasa tanto en el cervantismo, se ha hablado mucho y al mismo tiempo muy poco. Me refiero a aque- llos regocijos que habrían tenido lugar en el poblado peruano de $\mathrm{Pausa}^{2}$, hacia 1607, en honor al proveimiento de Juan de Mendoza y Luna-marqués de Montesclaros-

\footnotetext{
* Università Ca’ Foscari (Venezia) / Universidad de Sevilla Email: lauraagar.pazrescala@unive.it.

2 Es muy frecuente encontrar también la forma 'Pauza'. Visto que la tendencia no es del todo clara, para este artículo emplearé 'Pausa', por ser, al menos, la opción ortográfica que la tradición crítica prefiere. 
como virrey del Perú. Ha causado asombro tantas veces la afirmación de que, a solo dos años de su publicación, sería la segunda noticia más antigua de algún tipo de teatralización del Quijote 3 . Parte de dicho asombro se debió al hecho de que estos fastos se hayan realizado en Pausa y no en una de las capitales virreinales; sin embargo, como veremos, los que ahora parecen espacios marginales no siempre, ni a todos, dieron la misma impresión. Estas fiestas se hicieron famosas desde que la Relación de las fiestas que se celebraron en la corte de Pausa ... fue dada a conocer por Francisco Rodríguez Marín en $1911^{4}$. El manuscrito narra la dramatización de un torneo ecuestre, para el cual se presenta una interesante gama de caballeros, entre los cuales aparece don Quijote. Irving Leonard [1953] colaboró a dar sustento al renombre de estas fiestas al hablar de la circulación de libros de caballería en los virreinatos españoles de ultramar y al mostrar los acuerdos comerciales que quedan como prueba de la profusa cantidad de ejemplares que llegaron a América de la primera edición del Quijote (para esto sigue una estela que ya había marcado en su conferencia el mismo Rodríguez Marín y que, poco después, comienzan a repetir estudiosos de las primeras décadas del siglo XX [Francisco de Icaza 1918]). Esta relación de fiestas, por décadas, pasó de boca en boca, sin que nadie se detuviera a estudiarla cuidadosamente. Hoy el panorama ha cambiado, principalmente por la edición anotada de la relación de fiestas que en 2005 propusieron José Manuel Lucía Megías y Aurelio Vargas Díaz Toledo y por algunos estudios más como, por ejemplo, los de Raquel Chang Rodrígez [2007] y Susana Antón Priasco [2007; 2009].

Gracias a los citados estudios se ha hablado de la manera en la cual se compone la fiesta narrada en el manuscrito, se ha comenzado a interpretar la forma en que las jerarquías sociales se representan en ella, se han hecho recuentos de los personajes teatralizados, se ha intentado entender la manera en la cual se interpreta a don Quijote. Se ha comenzado a repasar, en suma, lo que viene narrado en la relación descubierta por Rodríguez Marín. Pero, todavía quedan preguntas de base por responder. ¿Cómo es posible que estas fiestas hayan siquiera tenido lugar? ¿Cuál es su contexto? Algunos de los estudiosos que hasta ahora se han hecho cargo de estos regocijos tienen en cuenta, aunque sea de manera implícita, el hecho de que Pausa tuvo una relevancia hoy un tanto olvidada. Así, Raquel Chang Rodríguez [2007], antes de proponer un análisis del torneo, se detiene a remarcar que Pausa estaba en una importante zona de minas de plata y cobre (más adelante, retomaremos este tema). Sin embargo, continúa a ser vox populi la afirmación de que unas onerosísimas y quijotescas fiestas se montaron en 1607 en una ciudad marginal del Perú, afirmación que ofrecería a la historia solo dos posibilidades: o la relación de fiestas no es del todo verídica, o Pausa tenía en esos años una relevancia que todavía hay que comprender. Esta reflexión fue la que me llevó a plantearme que no había manera de entender, sin caer en el ensueño, esta famosa teatralización del Quijote si no se prestaba más atención a la historia local de Pausa: ya sea a la tradición festiva que podía haber desarrollado, ya sea a su situación política y económica a inicios del siglo XVII.

El problema es, por un lado, que la tradición festiva del Virreinato de fines del siglo XVI e inicios del siglo XVII está en proceso de ser comprendida, sobre todo para lo que concierne a las ciudades menos centrales; y, por otro lado, que la historia local del actual departamento de Ayacucho -en cuyo límite meridional se encuentra Pausa- está en pañales. Y ni qué decir de lo marginada que ha quedado la historia de la provincia de Parinacochas, de la cual fue capital Pausa durante el periodo virreinal ${ }^{5}$. Esta carencia ha ocasionado que la renombrada teatralización del Quijote de 1607 quedara en el vacío, sin un sostén histórico, y se convirtiese, como suele suceder en estos casos, en una suerte de mito. Tanto para el cervantismo como, y sobre todo, para la misma ciudad de Pausa. Donde la memoria de que don Quijote apareció en estas fiestas se ha convertido en un eje identitario. Incluso el 2003 la Alcaldía decidió otorgar a Pausa el grado de capital cervantina de América (nombramiento que, a nivel internacional, si es que fue conocido, nunca fue reconocido $)^{6}$. Si uno hace una búsqueda en internet sobre el cervantismo en Pausa, encontrará una oleada de blogs y noticias informales que dan cuenta de un verdadero fenómeno de apropiación y reformulación cultural de lo que inicialmente era un fragmento de la relación de fiestas dada a conocer en 1911 (anónima y sin datación). El precio a pagar para forjar una identidad cultural y literaria sobre la base del cervantismo fue, como podría suponerse, dejar de lado el problema histórico que planteaba el suceso e inventarle una fecha apócrifa para que pueda ser conmemorado: en las páginas de divulgación dedicadas a la ciudad

Se dice que el Quijote se representa por primera vez durante los fastos celebrados en Valladolid en 1605 por el nacimiento del infante Felipe IV. Sin embargo, en el caso de estas celebraciones, tenemos solamente noticia de que un portugués aparece caricaturescamente vestido de don Quijote junto con otro que viene de Sancho; por ende, es muy difícil hablar de una verdadera teatralización. El episodio se encuentra en la Fastiginia del escritor portugués Pinheiro da Veiga. Aquí se narra que, en medio a los festejos de toros y cañas realizados para el futuro príncipe, en cierto momento "en medio de esta universal folganza, para que no faltara algo de mojiganga o entremés, apareciose un don Quijote que iba en la delantera solo y sin compañía, como aventurero, la cabeza cubierta de un enorme chapeo, en los hombros un buen capote de bayeta con mangas de lo mismo, los calzones de velludo y buenas botas con espuelas de pico de gorrión. Iba batiendo las ijadas a un pobre cuartago rucio [...] Seguíale su escudero Sancho Panza, el cual llevaba calados unos anteojos en señal de autoridad [...]” [en Rodríguez Marín 1911: 51]. Es interesante la interpretación de este episodio por Abraham Madroñal [2007], quien, más que ver aquí una primera teatralización, ve la manera en la cual don Quijote se va conformando en el imaginario como personaje cómico de traza entremesil.

4 En las dos famosas conferencias que dictó el 11 y el 17 de marzo de 1911 en el Centro de Cultura Hispanoamericana de Madrid. Las cuales posteriormente fueron recopiladas en su libro El Quijote y don Quijote en América. El manuscrito de la relación se encuentra conservado en: CSIC, Biblioteca Central, Archivo Francisco Rodríguez Marín, E IV, varios, caja 85, 4.

Ahora pasó a ser capital de la provincia de Páucar del Sara Sara creada en 1985 [Pomacanchari 2017: 272].

6 Lo hizo a través de la resolución municipal 031-2003 MPPSS, emitida el 26 de abril del 2003 bajo el mandato del alcalde Ítalo Villaverde Huaita. Un ejemplo de la manera en la cual los pobladores de Pausa se apropiaron de este imaginario son los "Saludos a la Capital Cervantina en sus 402 años", una breve nota periodística escrita justamente por Villaverde Huaita y publicada el 17 de marzo del 2016 (se publicó en la siguiente página web dedicada íntegramente a la ciudad de Pausa: <https://pauza.com/saludos-a-la-capital-cervantina-en-sus-402-anos/>). 
-incluyendo la tan consultada Wikipedia- se dice que la fiesta tuvo lugar el 19 de octubre de 1607, dato que no tiene ningún tipo de sostén documental ${ }^{7}$.

Así pues, es por respeto a esta identidad que propongo releer la relación manuscrita intentando entender, en contexto, su contenido. Hay que tener en cuenta, además, que nunca se ha resuelto el misterio de la procedencia del manuscrito, lo que hace más imperativa la necesidad de comprender si su contenido se ajusta o no a una determinada historia local.

En primer lugar, ¿qué tipo de fiestas se nos narran $\mathrm{y}$ a qué tradición podrían responder? El manuscrito cuenta que cuando en Pausa se enteraron de que se había proveído al marqués de Montesclaros como virrey del Perú salió una encamisada ${ }^{8}$ de cuarenta caballeros hacia la plaza para colgar un cartel donde en los siguientes diez días debían apuntarse los caballeros que desearan participar de unas justas en honor al nuevo mandatario. Se trataría, en palabras de Susana Antón Priasco, de la llamada a formar parte de un "torneo dramatizado" [2007: 154]. Diez días después tendrían lugar las fiestas. El mantenedor del torneo sería el corregidor de la ciudad.

Se nos narra la entrada de siete trabajados carros alegóricos ${ }^{9}$, todos con uno o más caballeros y sus respectivos padrinos. Los participantes se presentan disfrazados con mucha gala y llevando un suntuoso cortejo en el que no falta la música y la danza. Vemos pasar tantas chirimías, atabales y enorme cantidad de indígenas que eran quienes podían hacer numerosas las comitivas. Cada caballero, o a veces su padrino, se bate con el mantenedor o con el dios Baco, quien había hecho su entrada en escena en el rol de teniente del primer caballero que se enfrentó al mantenedor y había causado gran regocijo, como era de esperarse, pues daba de beber a la gente. Cuando los carros alegóricos entran, en ellos se organiza una suerte de representación, en la cual a veces se establecen pequeños diálogos y siempre se presentan, a través de variados mecanismos, las "letras" (lemas) de los caballeros, que vienen declaradas en la relación escrita. Luego, los caballeros juegan a las lanzas y quien gana se lleva un premio que puede ofrecer a una de las damas del público. En general, gana el mantenedor o el dios Baco. Al final, entra un último carro, falto de caballero, pero rico en colación para los asistentes.
Dadas las intenciones de este artículo, no me detendré ahora en el análisis de cada una de las entradas. Don Quijote, presentado como el Caballero de la Triste Figura, aparece en el cuarto carro:

A esta hora asomó por la plaza el Caballero de la Triste Figura, don Quijote de la Mancha, tan al natural y propio de como le pintan en su libro, que dio grandísimo gusto verle. Venía caballero en un caballo flaco, muy parecido a su Rocinante, con unas calcitas del año de uno y una cota muy mohoza, morrión con mucha plumería de gallos, cuello del dozavo y la máscara muy al propósito de lo que representaba. Acompañábanle el cura y el barbero con los trajes propios de escudero e infanta Micomicona que su corónica cuenta. Y su leal escudero, Sancho Panza, graciosamente vestido, caballero en su asno albardado y con sus alforjas bien proveídas y el yelmo de Mambrino; llevábale la lanza y también sirvió de padrino a su amo, que era un caballero de Córdoba de lindo humor, llamado don Luis de Córdoba, y anda en este reino disfrazado con nombre de Luis de Galves. Había venido a esta fiesta por juez de Castrovirreina [Relación de las fiestas ...: fols $3 \mathrm{v}-4 \mathrm{r}]^{10}$.

Su burlesca aparición viene acompañada de un lema de no menor talante, tres versos de cabo roto, siguiendo la tradición de la Urganda la Desconocida de los preliminares del Quijote:
Soy el audaz don Quijó
y maguer que desgraciá,
fuerte, bravo y arriscá
[Relación de las fiestas...: fol. 4r]

¿Cómo explicamos esta aparición en Pausa? Es verdad que para 1607 no era novedad en el Virreinato que se representaran torneos caballerescos. En esta ocasión, se combinan varias tradiciones españolas. En primer lugar, en Lima, que fungía de corte y modelo para el territorio, era ya usual para los recibimientos de los virreyes mandar entre otras cosas que se realizaran juegos de cañas ${ }^{11}$, en los cuales, disfrazados de caballeros, participaban los principales de la ciudad ${ }^{12}$. Los juegos de caña, de tradición medieval y cortesana, vinculados directamente

\footnotetext{
Páginas como: <www.pauza257.blogspot.com> (fecha de consulta: 18/X/2019); <www.artedelapalabra.wordpress.com> (fecha de consulta: 18/X/2019); <www.cronicasdepauza.blogspot.com> (fecha de consulta: 18/X/2019).

8 "Otro tipo de diversiones ecuestres eran las llamadas encamisadas, que solían tener lugar de noche, y en las que se reunían varias cuadrillas de caballeros para recorrer las calles y plazas de la ciudad, montados a caballo y con hachas encendidas en las manos en señal de regocijo" [Ferrer Valls 2003: 33]. El término 'encamisada' ya lo explicaría en sus Ejercicios de la Gineta en 1643 Tapia Salzedo, remarcando que en estas ocasiones no se llevan ni libreas, ni máscaras, pues las encamisadas se organizarían repentinamente ante una buena nueva [Fernández Truan y Orthous 2012: 19-20].

9 Los protagonistas principales de estos carros representan: 1) el caballero Bradaleón (quien entra con un teniente que será uno de los protagonistas de la fiesta: el dios Baco); 2) cinco aventureros que jugan a las cartas: el "juego de la primera"; 3) un caballero Inca; 4) don Quijote; 5) el Caballero de la Selva; 6) el Caballero Venturoso; 7) el Dudado Furibundo (caballero moro).

10 Transcribo el fragmento directamente del manuscrito modernizando todas las grafías cuya modificación no tenga trascendencia fonética.

11 Los recibimientos de virreyes organizados en Lima-documentados ampliamente en actas capitulares de la ciudad- han sido ya bastante estudiados. Destaco ahora: Guillermo Lohmann Villena [1945]; Rafael Ramos Sosa [1993]; Alejandra Osorio [2006; 2008].

12 La descripción de los juegos de caña realizada por Bernardo J. García García [2003] resulta muy útil para imaginar estos regocijos: "se componían de una serie de cuadrillas de caballeros, cada una con cuatro, seis u ocho miembros según la amplitud de la plaza donde se realizaba. Iban montados en sillas de jineta, ataviados con libreas diferentes por cada cuadrilla, ricamente adornadas con bordados, plumas y pasamanería. En su brazo izquierdo portaban una adarga (escudo de cuero en forma ovalada o de corazón) donde estaba representada la divisa y el mote que identificaba a la cuadrilla, dejando el derecho libre para jugar las armas [...] La cuadrilla que iniciaba el juego atravesaba la plaza tirando las cañas contra la cuadrilla adversaria que se defendía con sus adargas, y perseguía a la atacante a galope tendido. Sucesivamente se iban cargando unas cuadrillas a otras. Los jueces determinaban los premios según el lucimiento de las libreas y la calidad de las monturas, la armonía de la cuadrilla en las carreras
} 
con la hípica, tenían lugar principalmente cuando los festejos estaban relacionados con la corte. Así pues, los vemos aparecer sistemáticamente también en las juras reales que se hacían en el Virreinato o en los acompañamientos a las fiestas regias. Un ejemplo cercano a los fastos de Pausa son los juegos de caña que en 1606 se realizan en Lima por la noticia del nacimiento del infante Felipe. En este sentido, Susana Antón Priasco [2009] lee la fiesta de Pausa como una de las maneras que tenía la élite regional de identificarse con la clase dirigente monárquica y de constituirse así en "corte virreinal": un tipo de corte que manejaría su propio "sentido de nobleza”, más ligado a la adquisición de poder y de riquezas que a la sangre. De hecho, según propone la citada historiadora, ninguno de los protagonistas de la fiesta - de los cuales hablaré más adelante- puede jactarse de nobleza de sangre, salvo Juan de Larrea Zurbano, corregidor de Pausa hasta 1606, cuyo nombre cobrará importancia, a su vez, para las conclusiones de este artículo.

Fuera de Lima, tampoco es extraño encontrar manifestaciones de regocijo de tradición caballeresca, parece haber sido parte de la identidad de la clase gobernante o, al menos, de la identidad que esta, una vez estabilizada la conquista, estaba intentando construirse. Pero las fiestas de Pausa no son unos juegos de cañas simples, como creo haber expuesto. Son una dramatización compleja. La segunda tradición, de impacto en el Virreinato, que pudo haber influido es la de las famosas representaciones de batallas. Por un lado, están las fiestas de moros y cristianos. Este tipo de celebraciones, en las cuales, proponen los estudios de Milena Cáceres Valderrama ${ }^{13}$, se escenificaban combates como el de los doce pares de Francia, estaría más bien relacionado con lugares un tanto apartados de las ciudades capitales. Son escenificaciones que en algunos pueblos del Perú se siguen realizando. Es una tradición que se ha transmitido de manera principalmente oral y es muy difícil establecer exactamente cuándo tuvo su inicio, pero todo parece indicar que al menos desde el siglo XVII era una práctica recurrente. Por esto, es muy interesante notar que uno de los caballeros de Pausa habría sido precisamente un moro que debía batirse con un cristiano. Siguiendo esta misma estela, aparece también otra tradición, muy compleja y de la que quedan muy pocos rastros: la representación de batallas contra indios, como la que entrevemos, sin ir muy lejos, por la aparición de un caballero Inca entre los participantes de nuestro torneo ${ }^{14}$.

Anterior a los festejos de Pausa serían, por su parte, las narraciones que conservamos de certámenes de estilo caballeresco en Potosí, el corazón minero y económico del Perú en aquel entonces. Arzáns de Orsúa y Vela cuenta que en 1578, para las fiestas del patrono Santiago, en la Villa Imperial se habrían llevado a cabo, durante varios días, espectaculares festejos caballerescos: una sortija en la cual el mantenedor "y otros 80 caballeros aventureros entraron a la plaza con varias, admirables y muy costosas invenciones"; al día siguiente "torneos y escaramuzas de los caballeros, con muchas invenciones"; por otros cuatro días: "se representaron varios pasos de caballería, así en teatros ${ }^{15}$, como con caballos y lanzas en la plaza"; y, para finalizar: "sobre todo se hizo una grande y galantísima justa" [Historia de la Villa Imperial, 5, 8: 175]. Así pues, según la versión de la historia potosina que nos ofrece Arzáns, la élite minera habría sido bastante aficionada a este tipo de celebraciones originalmente cortesanas: en las justas, por ejemplo, el corregidor entra acompañado de "treinta caballeros azogueros" [Historia de la Villa Imperial, 5, 8: 175].

Por su parte, fray Diego de Ocaña narra en sus memorias los fastos que en 1601 habrían tenido lugar en La Plata y Potosí por la instauración en ambas ciudades de la imagen jerónima de la Virgen de Guadalupe ${ }^{16}$ [ed. Peña, 2013: 551-588]. En el caso potosino, una de las fiestas que se narra es la que tuvo lugar el 30 de septiembre de 1601 (continuando los festejos inaugurados el 8 de septiembre -fiesta de la Virgen de Guadalupe- y en coincidencia con el día de San Jerónimo). Se trata de un torneo en honor a la Virgen. La tradición, aplicada en este caso al ámbito religioso, es la misma que llevará seis años después a los regocijos de Pausa. El torneo en honor a la Virgen es designado como sortija, pues, efectivamente, los caballeros que se presentan compiten embocando lanzas en una sortija. Como en Pausa, se presenta un grupo de singulares caballeros ("aventureros") que hacen su aparición en la plaza principal ${ }^{17}$ en espectaculares carros alegóricos, acompañados de numerosas comitivas que representan ciertas escenas que definen el tipo de caballeros que son y lo que significan. Por ejemplo, como en el caso de Pausa, uno de los caballeros que aparece con más lucimiento representa al Inca mismo. Este entra, con una comitiva numerosísima de indígenas, en un carro que vendría a ser una peña encantada de la que solo logra salir con la colaboración de una dama, la Fe. Detrás de la comitiva, viene también una enorme sierpe (manejada por varias personas desde dentro del disfraz) que se come al caballero Inca ni bien Fe lo libera de la peña. Gracias a la devoción de sus súbditos indígenas hacia la Virgen, va en socorro del Inca un caballero llamado Predicación, quien vence a la sierpe. Como en otros acompañamientos de este torneo, sorprende el uso de muchísimo fuego. Tanto la peña como la serpiente de las que el Inca se libera acaban ardiendo en un espectáculo de fuegos artificiales y

y la habilidad mostrada en el ataque y la defensa" [180].

13 Donde mejor se hallan expuestos estos temas es en el último libro de dicha estudiosa: El emperador Carlomagno y los doce pares de Francia: la fiesta de moros y cristianos en los Andes del Perú [2018].

14 Paul Firbas ofrece una interpretación interesante de la manera en la cual aparece el Caballero Antártico (el caballero vestido de Tupa Inca): desde su mismo apelativo, Antártico, este caballero llevaría la representación del Inca al espacio de "la épica y la cosmología", a un espacio previsto por la tradición española, a un espacio en el cual lo verdaderamente indígena desaparecería - los indios actuando de indios- en favor de una versión imaginada por la cultura europea [2000: 353-356].

15 Entendidos, para la época y por el contexto, como tablados.

16 Es a estas fiestas y a estas memorias a las que debemos la primera obra teatral que se conserva para todo el territorio que abarcaba el Virreinato del Perú: La Comedia de Nuestra Señora de Guadalupe, compuesta por el mismo Ocaña e incluida en su integridad en sus memorias.

17 Para un análisis de la conformación de estas fiestas alrededor del epicentro de la plaza: Alvarado Teodorika, 2007. 
artillería. Finalmente, el Inca logra competir en la sortija con el mantenedor del torneo y gana.

Estas fiestas en Potosí, costeadas por los hombres más ricos de la más rica de las ciudades, llegan a niveles de esplendor que Pausa no alcanza. Lo importante es notar lo singular que resulta que la tradición de festejos caballerescos -de tradición cortesana- nos lleve en este periodo de la historia virreinal hacia los importantes yacimientos argentíferos. La riqueza, al fin y al cabo, tiene su propio tipo de corte. De hecho, el ejemplo de Potosí, por excelencia la ciudad de la plata, pudo haber hecho de modelo para otros centros mineros: en ese caso, una repercusión en las zonas más conectadas con Huancavelica -como Pausa- no sorprende. Volveré sobre el tema al hablar del contexto local de la fiesta, pero la presencia de Potosí en las fiestas de Pausa está documentada en el mismo hecho de que uno de los tres jueces del torneo es un minero potosino: Cristóbal de Mata.

Hago este pequeño recorrido para decir que hacia 1607 en Perú era posible que toda esta tradición festiva, en la cual los principales de la ciudad jugaban a ser caballeros medievales, llevara al tipo de dramatización que se expone en el manuscrito. En este caso, la aparición de un caballero como el Quijote habría caído como anillo al dedo o sortija a la lanza. Más de una vez se ha dicho que la presencia del Caballero de la Triste Figura en los festejos en los que viene representado a inicios del siglo XVII respondía a una interpretación en la cual se consideraba a don Quijote como un caballero más de las tantas sagas, aunque, claro, dotado de un extra de comicidad. Así, por ejemplo, han explicado Lucía Megías y Vargas Díaz Toledo [2005] el hecho de que apareciera retratado de manera tan distinta a la del libro: con su exagerado morrión coronado de plumas y con el prestigioso cuello de dozavo (la duocécima parte de una de vara). Por su parte, José Julio Vélez-Sainz [2007] propone que el antártico don Quijote se constituiría en una alusión, de corte carnavelesco, a los soldados españoles de la época. Una mezcla, entonces, quizá, entre caballero de saga, soldado renacentista/conquistador y algo muy distinto: ese personaje caballeresco creado, en la literatura cervantina, por la imaginación lectora de Alonso Quijano. En fin, la particularidad mayor de nuestro caballero es que, dentro de la ficción de la fiesta, es un no caballero (¿un soldado? ¿Alonso Quijano?) haciendo de caballero y fallando en el intento; es representado en compañía de otros personajes (el cura, el barbero) a su vez disfrazados (de princesa Micomicona y de escudero). Este caballero es un golpe de ironía y modernidad. Es el reverso de la fiesta. Podría ser una suerte de desafío a todos los demás caballeros a caer en su propia condición de farsa y a gozar todavía más del juego: así, sin dar en el blanco siquiera con una lanza, rompiendo incluso en el cabo los versos de su lema. Quizá, solo quizá, don Quijote es aceptado tan pronto como parte de un festejo virreinal porque todos los festejos virreinales de tono caballeresco tuvieron desde siempre algo de quijotesco.
Pero, más allá de estas interpretaciones y de la posibilidad de rastrear en el mismo territorio una tradición para el montaje de las fiestas, queda la pregunta de cómo es posible que regocijos de este calibre tuvieran lugar en un poblado peruano considerado marginal. Para responderla, me basaré, por un lado, en bibliografía sobre la historia de Pausa y, por otro, en un expediente judicial que he encontrado en la sección de Corregimiento del Archivo Regional del Cusco y que pertenece justamente a $1607^{18}$, el año del torneo.

Por el mismo manuscrito de las fiestas, sabemos que el mantenedor fue el corregidor de Parinacochas. Rodríguez Marín [1911] lee mal el texto y lo confunde con el primer caballero que combate contra el mantenedor; así, dice que el corregidor es Pedro de Salamanca. Aurelio Miró Quesada [1962] se da cuenta del error y lo señala, porque, además, se remite a las actas capitulares de la ciudad de Lima, donde queda claro que a finales de 1606 se nombra por corregidor de Parinachochas a Francisco de Ávala y Norueña, quien no es mencionado en ninguna parte de la relación de fiestas. Este detalle es singular, pues, a pesar de las aclaraciones de Miró Quesada, parte de la bibliografía posterior continúa mencionando a Pedro de Salamanca como corregidor. Influye el hecho de que incluso un libro como la Monografía de la provincia de Parinacochas [1950], basándose de seguro en los comentarios que hasta mediados de siglo se habían hecho sobre las quijotescas fiestas, presente a Pedro de Salamanca como corregidor: lo que es sintomático de cuánto influyó el estudio de estos regocijos incluso en la manera en la que se comenzó a plantear una historia de la provincia.

Los nombres que sí se mencionan en el manuscrito son los de los jurados del torneo, de la mano de los cuales quiero explicar por qué Pausa no era entonces el espacio de marginalidad que ahora se imagina. Y quizá sean estos mismos nombres los que nos lleven a entender en qué contexto y con qué objetivos tuvieron lugar estas fiestas.

El primero de los jueces es fray Antonio Martínez, quien, para la época, como prueban ciertos documentos de compra y venta, era el prior del convento dominico de San Cristóbal de Pausa, sobre el cual hasta hace unas décadas no se sabía nada. Pero, desde que embrionariamente se comenzó a rescatar el archivo del Convento de Santo Domingo de Lima ${ }^{19}$, el padre Juan Bautista Lassegue encontró algunos documentos que dan cuenta de su importancia.

El Convento de San Cristóbal habría sido fundado originalmente -en un poblado cercano de Pausa- según el modelo de una capellanía, luego habría adoptado más bien las formas de una parroquia de indios y sería solo desde 1586 que tenemos certeza de que se refunda, con muchas más atribuciones, en Pausa. La tesis del padre Lassegue [1984] es que en la década de 1580 se decidió refundar el convento en Pausa porque ya se delineaba como la cabeza administrativa de la provincia. De una

\footnotetext{
18 Archivo Regional del Cusco, sección Corregimiento, Causas ordinarias, legajo 3, cuaderno 10. En el primer folio: “provisión para tomar cuentas y necesidades de Juan de Larrea Surbano, corregidor, sobre las cuotas reales de la provincia de Parinacochas".

19 El Archivo de la Provincia Dominicana de San Juan Bautista del Perú estuvo cerrado al público general hasta que el 2015 Melecio Tineo Morón comenzó a organizarlo y a recuperar el material documental en deterioro. Antes, muy pocas personas (como el padre Lassegue, que era religioso de la orden) podían acceder al material para darle uso en la investigación histórica.
} 
provincia cuya administración dependía en gran parte de los poderes caciquiles, que fueron probablemente los que impulsaron la fundación del convento. En palabras de Lassegue: "la petición para fundar un convento en Pausa corresponde a un poder civil y religioso bien asentado por las mismas comunidades indígenas" [1984: 500-501]. Es decir, la provincia de Parinacochas se caracterizaba por la gran cantidad de comunidades indígenas que albergaba, las cuales tenían que rendir cuenta a los indios caciques (una de las estrategias que utilizaron los españoles para organizar a las poblaciones indígenas a través de modelos de control prehispánicos). Los caciques, en una provincia como Parinacochas, eran muy importantes y estaban a cargo de gran cantidad de indígenas. En las fiestas de Pausa, vemos aparecer a los caciques en una posición de relieve, aunque, claro, subordinada a la de los caballeros españoles. Inicialmente, cuatro caciques entran a caballo como padrinos del caballero dios Baco. Por su parte, el Caballero Antártico, que es el que entra vestido de Tupa Inca, viene con un acompañamiento de más de cien indios vestidos de colores y, a la cabeza de todos ellos, como capitán, el cacique del repartimiento de Pomatambos (uno de los cuatro que entonces componían Parinacocha).

Así pues, este primer juez representa uno de los poderes que regían sobre el territorio, el poder religioso. El cual, a su vez, estaba muy relacionado con otra de las grandes instituciones organizativas, la de los caciques.

El segundo juez, Cristóbal de Matas, era un minero potosino. Lo que nos lleva a otro eje de poder, sobre el que algo ya dijimos al hablar de Potosí: la economía minera. Toda la región de Huamanga - Ayacucho - era importantísima en lo que concernía al comercio de mineral. Era un punto intermedio entre las minas de mercurio de Huancavelica y los grandes centros mineros charqueños. Así las cosas, a inicios del XVII no estamos, como se ha solido afirmar, ante una región marginal, ni en lo económico, ni en lo administrativo. En Huamanga, como explican en su libro Gonzáles Carré, Urrutía Ceruti y Levado Peña [1997], se formó, por la gran cantidad de indígenas, una élite de encomenderos y por la gran cantidad de mercurio de la región vecina, una élite de mineros. Es decir, quizá, era el lugar perfecto para que se hicieran unas fiestas como las de Pausa. Sin ir muy lejos, don Luis de Córdoba, que es quien interpretaría a don Quijote, habría sido, según cuenta el mismo manuscrito, juez de Catrosvirreina. Castrovirreina perdió toda su importancia en época republicana, por lo que hoy no nos dice nada, pero en el siglo XVII era un paso para el comercio del azogue y, además, era un centro minero. Por ende, lo más probable es que nuestro don Quijote haya podido presentarse con tanta pompa burlesca porque Luis de Córdoba pertenecía, justamente, a una élite minera.

Ahora bien, el tercer juez del torneo es el que más llama la atención, pues se relaciona directamente con el expediente encontrado en el Cusco y porque, además, me conducirá a tentar una interpretación conclusiva sobre el contexto de estas fiestas. Se trata del excorregidor de la provincia de Parinacochas: Juan de Larrea y Zurbano.

Por el expediente conservado en el Cusco nos enteramos de que, a finales de 1606, cuando entra el nuevo corregidor, Francisco de Ávala y Norueña (sí, el que nunca se menciona en la relación de fiestas), este da orden para tomar cuentas sobre las cuotas reales al anterior corregidor. Abiertas las cajas reales, se descubre que faltan más de nueve mil pesos de plata ensayada y más de siete mil de plata corriente. El nuevo corregidor procesa al anterior, al juez de nuestro torneo; el cual, finalmente, acaba preso (seguro por un periodo muy breve) y es sometido - por no contar con el dinero para saldar la deuda - a un secuestro de bienes. Dicho secuestro, que viene detallado en el expediente, es muy extraño, pues son bastante pobres los bienes del excorregidor, lo que lleva a que no pueda cubrir el dinero faltante de las cajas reales. Así, Ávala y Norueña deriva la causa a los fiadores del excorregidor que entonces eran residentes en el Cusco. El largo expediente es la lucha de estos fiadores por liberarse de tener que pagar tal suma de dinero por una deuda que no era suya: por supuesto, una de las cosas que alegan es que en Parinachochas no se habría realizado con suficiente diligencia el proceso contra Larrea Zurbano.

Hacia agosto de 1607 la situación era muy tensa. Los fiadores del Cusco inculpaban de mala praxis tanto al nuevo como al anterior corregidor. Una posibilidad, efectivamente, es que Ávala y Norueña hubiera salvado a Juan de Larrea y Zurbano de su obligación. Sin ir muy lejos, quizá un secuestro de bienes mal hecho fue la táctica para lograr que la deuda pasara a los fiadores. El hecho de que pudo haber un acuerdo entre el anterior y el nuevo corregidor podría hallar una de sus pruebas en las fiestas de Pausa, donde el corregidor es el mantenedor y el excorregidor el juez.

Durante casi un año, desde finales de 1606, se intentó resolver esta causa, pero no se llegó a un acuerdo. La Audiencia de Lima, en sede vacante, no terminaba para agosto de 1607 de dar una respuesta definitiva. Muy probablemente estaban esperando que dirimiera el nuevo virrey que estaba por llegar. Ya en julio Montesclaros había terminado su gobierno en la Nueva España y desde diciembre comenzaría a gobernar el Virreinato del Perú. Visto este expediente, no resulta extraño que, ante la noticia de que se había proveído un nuevo virrey, las autoridades de Parinacochas decidieran que lo mejor era comenzar, lo antes posible, a congraciarse con él. Considerando estas circunstancias y que era un momento en el cual la región de Huamanga estaba intentando mostrar independencia en relación al $\mathrm{Cusco}^{20}$, es natural que muchos de los hombres influyentes de Parinacochas se hubieran sumado a los fastos para el virrey entrante.

Una de las particularidades de las fiestas de Pausa es que no se hacen a la llegada del virrey, no se hacen

\footnotetext{
20 Esto principalmente en vistas de la separación de la diócesis de Huamanga de aquella del Cusco. Suceso que finalmente tendrá lugar en 1609, justamente bajo el gobierno del virrey Montesclaros. Lohmann Villena [2001: 242-243] cita varios documentos que permiten comprender la situación de los corregimientos peruanos en la primera década del siglo XVII. Entre ellos se puede acudir a AGI (Archivo Genera de Indias), Lima 275, fols 655-673: documento colacionado por Lohmann Villena que contiene el auto de creación de las diócesis de Cusco, Huamanga, Arequipa y Trujillo.
} 
ante los ojos del virrey. Es una eclosión de algarabía que tiene que llegar al virrey a través de la escritura.

Esto puede explicar, por ejemplo, que nunca se mencione el nombre del mantenedor y corregidor entrante, de Ávala y Norueña. Quizá, para él, lo esencial era el momento mismo de la fiesta, cuando hacía patente su poder sobre la provincia. La relación de las fiestas, por otra parte, probablemente era - aprietos legales de por medio - más importante para el excorregidor. Para mostrar su dignidad. Para mostrarse ante el virrey, a través de la escritura, como uno de los personajes más relevantes de Parinacochas; él que, además, estaba casado con doña María de Peralta, dama perteneciente a una de las familias más importantes de todo el territorio, hija del conquistador y fundador de Arequipa Diego de Peralta Cabeza de Vaca. Una prueba de esto es que, según cuenta la relación manuscrita, doña María de Peralta y las hijas que tuvo con Larrea Zurbano fueron las destinatarias de las ofrendas que los victoriosos caballeros donaron, como mandaba la tradición, a las damas del público. Ellas aparecen, en definitiva, como las princesas del torneo. Y, por si fuera poco, el narrador de la relación, cada vez que se refiere a doña María de Peralta, lo hace como "mi señora".

Al principio traje a colación los misterios que rodean el manuscrito de Rodríguez Marín. No conocemos su procedencia, ni quién, ni cuándo lo escribió. Luego de mis investigaciones y por los motivos expuestos creo que es factible que las fiestas sucedieran de una manera muy similar a la de la narración y que el Caballero de la Triste Figura apareciera en la plaza de Pausa. Creo que el estudio del manuscrito ayuda tanto a revisar ciertas tradiciones festivas, como a revalorizar la historia colonial de la provincia de Parinacochas. Pero creo, también, que no hay que olvidar que no estamos ante las fiestas mismas, sino ante su narración y, bien lo sabemos, la escritura no es inocente. En este caso, propongo como hipótesis que estamos ante una escritura que, junto con dar cuenta del lucimiento de la ocasión, tiene el objetivo de hacer honores a Larrea y Zurbano y su familia.

\section{Bibliografía}

Alvarado Teodorika, Tatiana (2007): "De las fiestas que destaca fray Diego de Ocaña en su relación. La Plaza como epicentro de la celebración”, Memorias del V Encuentro Internacional sobre Barroco, La Paz, Fundación Visión Cultural: 337-343.

Antón Priasco, Susana (2007): "El Quijote en una celebración cortesana en el Perú colonial. La fiesta como reflejo del funcionamiento de la sociedad virreinal”, en Lolo Begoña (ed.), Cervantes y el Quijote en la música: estudios sobre la recepción de un mito, Madrid, Ministerios de Educación y Ciencias/ Centro de Estudios Cervantinos:151-170.

- (2009): "Espectáculos cortesanos en la América española del siglo XVII: las fiestas como caso para el análisis de la relación entre la Corte y la Corte virreinal", Estudios de Historia de España, 11: 197-231.

Arzáns de Orsúa y Vela, Bartolomé (1965): Historia de la Villa Imperial de Potosí, La Paz, Plural/FCBCB/Casa Nacional de la Moneda, 2012.

Cáceres Valderrama, Milena (2018): El emperador Carlomagno y los doce pares de Francia: la fiesta de moros y cristianos en los Andes del Perú, Lima, Instituto Riva Agüero/Pontifica Universidad Católica del Perú.

Centro de Colaboración Pedagógica Provincial del Magisterio (1950): Monografía de la provincia de Parinacochas, Lima, CCPPM.

Chang Rodríguez, Raquel (2007): "El periplo peruano de don Quijote” en Julio José Vélez-Sainz y Nieves Romero Díaz (ed.), Cervantes and/on/in the New World, Delaware, Juan de la Cuesta: 7-30.

García García, Bernardo: "Diversiones de la fiesta", Teatro y fiesta del Siglo de Oro en tierras europeas de los Austrias, Madrid, Sociedad Estatal para la Acción Cultural Exterior de España: 178-181.

Fernández Truan, Juan Carlos y Marie Helene Orthous (2012): “El juego de cañas en España”, Recorde: Revista de História do Esporte, 1 (vol. 5): 1-23.

Ferrer Valls, Teresa: "La fiesta en el Siglo de Oro: en los márgenes de la ilusión teatral”, Teatro y fiesta del Siglo de Oro en tierras europeas de los Austrias, Madrid, Sociedad Estatal para la Acción Cultural Exterior de España: 27-37.

Firbas, Paul (2000): "Escribir en los confines: épica colonial y mundo antártico" en Jose Antonipo Mazzotti (ed.): Agencias criollas. La ambigüedad colonial en las letras hispanoamericanas, Pittsburgh, Instituto Internacional de Literatura Iberoamericana: 191-213.

Gonzáles Carré, Enrique, Jaime Urrutia Ceruti y Jorge Levano Peña (1997): Ayacucho. San Juan de la Frontera de Huamanga, Lima, Banco de Crédito del Perú.

Icaza, Francisco de (1918): El Quijote durante tres siglos, Madrid, Renacimiento.

Lassegue, Juan Bautista (1984): "La fundación progresiva de un convento hospital en Parinacochas, diócesis del Cusco (15671586): apuntes de lectura e hipótesis de estudio", Revista andina, 2: 487- 511.

Leonard, Irving (1953): Los libros del conquistador, México, Fondo de Cultura Económica.

Lohmann Villena, Guillermo (1945): El arte dramático en Lima, Madrid/ Sevilla, Consejo Superior de Investigaciones científicas y Escuela de Estudios Hispanoamericanos.

- (2001): El corregidor de indios en el Perú bajo los Austrias, Lima, Pontificia Universidad Católica del Perú.

Lucía Megías, José Manuel y Aurelio Vargas Díaz Toledo (2005): “Don Quijote en América: Pausa, 1607 (facsímil y edición)”, Literatura: teoría, historia, crítica, 7: 203-244.

Madroñal, Abraham (2007): "Figurones de comedia y figurones de entremés”, en Luciano García Lorenzo (ed.): El figurón. Texto y puesta en escena, Madrid, Editorial Fundamento: 249-272. 
Miró Quesada, Aurelio (1962): El primer virrey poeta en América (don Juan de Mendoza y Luna, marqués de Montesclaros), Madrid, Gredos.

Ocaña, Diego de: “Comedia de Nuestra Señora de Guadalupe y sus milagros”, en Beatriz Peña (ed.), Memoria viva de una tierra de olvido. Relación del viaje al Nuevo Mundo de 1599 a 1607, Barcelona, Paso de Barca, 2013.

Osorio, Alejandra (2006): "La entrada del virrey y el ejercicio de poder en la Lima del siglo XVII", Historia Mexicana, 3 (vol. 55): 767-831.

- (2008): Inventing Lima: Baroque Modernity in Peru's South Sea Metropolis, New York, Palgrave Macmillan.

Peña, Beátriz (2013): Memoria viva de una tierra de olvido. Relación del viaje al Nuevo Mundo de 1599 a 1607, Barcelona, Paso de Barca.

Pomacanchari, Vivanco (2017): "Páucar del Sara Sara en Ayacucho. Historia Milenaria de Llaqtakuna: evolución, cultura y tradición”, Alteritas. Revista de estudios socioculturales andino-amazónicos, 7: 271-304

Ramos Sosa, Rafael (1992): Arte festivo en la Lima virreinal (XVI-XVII), Sevilla, Junta de Andalucía (Consejería de Cultura y Medio Ambiente, Asesoría Quinto Centenario).

Rodríguez Marín, Francisco (1911): El Quijote y don Quijote en América, Madrid, Librería de los sucesores de Hernando.

Vélez-Sainz, Julio José (2007): "Introduction: Cervantes and/on/in the New World”, en Julio José Vélez-Sainz y Nieves Romero Díaz (ed.), Cervantes and/on/in the New World, Delaware, Juan de la Cuesta: 7-30.

Villaverde Huaita, Italo (2016), "Saludos a la capital cervantina en en sus 402 años”, Pausa, < https://pauza.com/saludos-a-lacapital-cervantina-en-sus-402-anos/>, fecha de consulta: 18/X/2019.

\section{Manuscritos de archivo}

Provisión para tomar cuentas y necesidades a Juan de Larrea Suibano [sic], corregidor, sobre las cuotas reales de la provincia de Parinacochas, Archivo Regional del Cusco, Corregimiento, Causas Ordinarias, Cuaderno 10.

Relación de las fiestas que se celebraron en la corte de Pausa por la nueva de proveimiento de Virrey en la persona del Marqués de Montes Claros, cuyo grande aficionado es el corregidor de este partido, que las hizo y fue el mantenedor de una sortija celebrada con tanta majestad y pompa que ha dado motivo a no dejar en silencio sus particularidades, CSIC, Biblioteca Central, Archivo Francisco Rodríguez Marín, E IV, varios, caja 85, 4. 